\title{
Right to left shunting detection by contrast-enhanced transcranial color-coded duplex among patients with cryptogenic stroke
}

\author{
Samia Ashour Mohamed', Mohamed Ayman Saleh², Hala Mahmoud ELKhawas ${ }^{1}$, Eman Saleh ElHadidi \\ Ahmed ElSadek ${ }^{4^{*}}$ and Noha Lotfy Soliman ${ }^{1}$
}

\begin{abstract}
Background: Contrast-enhanced transcranial duplex (c-TCD) might be more sensitive than transesophageal echo (TEE) for detection of right to left shunting (RLS), which misses some cases with substantial RLS and might be valuable for prediction of recurrent stroke or transient ischemic attack in patients with PFO. Our aim is to detect sensitivity and specificity of contrast-enhanced TCD in detection of RLS among stroke patients with patent foramen ovale (PFO) in comparison to TEE.
\end{abstract}

Methods: TEE and contrast-enhanced TCD for cryptogenic stroke patients with PFO were done to detect right to left shunting.

Results: On testing characteristics of TCD in detecting RLS compared to the gold standard of TEE, TCD sensitivity was $85.7 \%$, specificity was $100 \%$, negative predictive value was $96.55 \%$, and positive predictive value was $100 \%$.

Conclusion: We concluded that PFO is considered an important hidden etiology for ischemic stroke. Contrastenhanced TCD is considered sensitive method for detection of right to left shunting among PFO patients.

Keywords: Right to left shunting, Cryptogenic stroke, Contrast-enhanced transcranial duplex, Transesophageal echo, Patent foramen ovale

\section{Introduction}

Cryptogenic stroke (CS) is defined as cerebral ischemia of obscure origin. The cause of CS remains undetermined because the event is transitory or reversible, investigations did not look for all possible causes, or because some causes truly remain unknown. CS is more frequent in younger than older patients and it was found that when it is properly investigated, the most frequent causes would be cardiac embolism, followed by vasculopathy, and coagulopathy [1]. Strokes may remain cryptogenic if diagnostic

\footnotetext{
* Correspondence: ahmedelsadek_79@yahoo.com

${ }^{4}$ Ain Shams University, 19/1/42, P.O. 11841, El Rehab City, Cairo, Egypt Full list of author information is available at the end of the article
}

evaluation is incomplete for one or another reason or in the presence of multiple competitive causes, such as atrial fibrillation (AF) and atherosclerotic stenosis in an ipsilateral relevant artery [2].

A PFO is a flap-like valve that connects the right and left atria. It is instrumental in the fetal circulation by allowing oxygenated blood to bypass the immature lungs and pass directly into the left atrium. A PFO typically closes after birth but may remain open in up to $25 \%$ of adults, creating a shunt between the right and left atria. A meta-analysis of case-control studies showed the prevalence of PFO is higher in cryptogenic stroke, specifically in patients younger than 55 years [3]. A proposed mechanism of ischemic stroke in the setting of an

\section{Springer Open}

(๑) The Author(s). 2021 Open Access This article is licensed under a Creative Commons Attribution 4.0 International License, which permits use, sharing, adaptation, distribution and reproduction in any medium or format, as long as you give appropriate credit to the original author(s) and the source, provide a link to the Creative Commons licence, and indicate if changes were made. The images or other third party material in this article are included in the article's Creative Commons licence, unless indicated otherwise in a credit line to the material. If material is not included in the article's Creative Commons licence and your intended use is not permitted by statutory regulation or exceeds the permitted use, you will need to obtain permission directly from the copyright holder. To view a copy of this licence, visit http://creativecommons.org/licenses/by/4.0/. 
atrial septal abnormality like PFO is paradoxical embolism from a distal source (deep vein thrombosis in the lower extremity or pelvis, or thrombi from the atrial septal defect or transient atrial arrhythmias). The embolus then migrates directly into the arterial vasculature through a cardiac atrial or ventricular septal defect, essentially bypassing the pulmonary circulation [4].

TCD is an alternative method for indirectly diagnosing PFO by assessing the presence of a RLS. It employs the functional assessment of the shunt using insonation of middle cerebral artery MCA during a venous injection of agitated saline and Valsalva maneuver. After contrast injection, bubbles enter the systemic circulation during this transient RLS, resulting in microembolic signals in the cerebral arteries that are detected by TCD. TCD utilizes a pulsed Doppler transducer that detects the velocity and intensity of cerebral arterial blood flow by spectral analysis. The trade-off between TCD and TEE for detection of RLS is still a matter of controversy. TCD might be valuable for prediction of recurrent stroke or transient ischemic attack in patients with PFO [5].

\section{Aim of the work}

To detect sensitivity and specificity of contrast-enhanced TCCD in detection of right to left shunting among stroke patients with PFO in comparison to TEE.

\section{Methods}

It is a cross-sectional study conducted during the period from July 2016 till August 2018. The sample consisted of 482 ischemic stroke patients admitted to the stroke unit during the period from July 2016 to August 2018 of which 55 patients were classified to be of undetermined etiology according to (TOAST) classification [6]. NIIHSS and MRS were done for all patients on admission and after 1 month.

\section{Inclusion criteria and patient selection}

- Age: more than 18 years. Clinical presentation of cerebrovascular stroke (defined as the presence of rapidly developing focal neurological signs or symptoms of vascular origin that persists for more than $1 \mathrm{~h}$ ) [7]. Routine diagnostic tools [routine lab, carotid ultrasound, trans-thoracic echocardiography (TTE), electrocardiogram (ECG)] were normal to categorize patient as cryptogenic stroke as minimum required diagnostic tools mentioned in American Heart and Stroke Associations [8].

- Cryptogenic stroke patients were excluded from enrollment if one of the following criteria was met:

- Age less than 18 years or more than 60 years
- Medically unstable patients or have contraindications to used investigations

- Patients who rejected enrollment in the study

\section{Methods}

Written informed consent was obtained from the patients participating in the study, or their first-degree relatives if the patient was unable to provide consent due to weakness or disturbed conscious level, after informing them about the study rationale and their right to withdraw from the study at any time without any consequences. All patients were subjected to history taking including personal data, past history, history of vascular risk factors, detailed history of current illness.

\section{General and neurological examination Laboratory investigations}

ESR, CRP, ANA, Anti DNA, anticardiolipin antibody, lupus anticoagulant, ANCA P and ANCA C, Protein C, protein $\mathrm{S}$, and antithrombin w were done for all patients to exclude autoimmune etiologies and hypercoagulopathies. CT brain to exclude intracerebral hemorrhage. MRI brain (Philips 1.5 Tesla) (diffusion weighted, Flair, T1, T2, and T2* images) and MRA. Transesophageal echocardiography (GE Healthcare, vivid E9 with 6 DT-D TEE probe) was done for detection of PFO and RLS. Agitated saline was injected and monitored to detect right to left shunting (without and then with Valsalva maneuver). TEE was also used to detect other findings: atrial septal aneurysm (ASA), intracardiac thrombi, and aortic atheromatous plaques. Forty-eight hours Holter ECG (Norav Holter NH-301). Contrast-enhanced transcranial color-coded duplex (esaote mylab 5, Italy using 2-4 MHZ phased array probe) was done for patients for detection of microembolic signals in the middle cerebral artery for confirmation of the presence of patent foramen ovale and presence of right to left shunting by using agitated saline consisted of $1 \mathrm{ml}$ of air vigorously mixed with $8.5 \mathrm{ml}$ of saline solution and injected into the antecubital vein via a three-way stopcock immediately after contrast preparation. If no microbubbles were detected after the first injection, then a further two injections were made with a Valsalva maneuver. Microembolic signals were considered positive if detected within $30 \mathrm{~s}$ from contrast injection and grading was considered grade 1 (microemboli 1-10), grade (microemboli 11-30), and grade 3 (microemboli 31-100) [9].

\section{Statistical analysis}

Statistical analysis was conducted using SPSS V24 (SPSS, IBM, Chicago, IL, USA). $P$ values were considered significant if $<0.05$. Descriptive statistics were used for patient demographics, chi-squared test was used to compare normally distributed demographics, likelihood 
ratio was used to compare abnormally distributed variables. $T$ test was used to compare means of NIH and mRs on admission and at 3 months, as well as age distribution. Kaplan-Meier survival curves were plotted to display the relation of time to Holter, and arrhythmia discovery.

\section{Results}

\section{Demographic data of CS patients}

Our study group consisted of 55 patients with cryptogenic cerebrovascular stroke included 34 males (61.8\%) and 21 females (38.2\%), and their ages ranged from 26 to 59 years with mean age of $39.11 \pm 8.319$ years.

\section{Transesophageal echocardiography findings}

TEE findings showed that 9 patients had interatrial septal aneurysm (ASA) (16.7\%), 16 patients had patent foramen ovale (PFO) (29.6\%) of which 10 patients showed positive shunting by TEE (using agitated saline, Valsalva maneuver, and abdominal compression); of them, 13 patients had RoPE score of 6 points or more, 4 patients had intracardiac thrombi (7.4\%), 5 patients had descending aorta plaques $(9.3 \%)$ only one of them had complex aortic plaque (which is defined as increased echo density and thickening of the intima $>5 \mathrm{~mm}$ with shaggy overlying echogenic material and marked irregularities in the intimal wall), and 2 patients had filamentous mass in relation to the aortic valve (3.7\%) (Table 1).

\section{Holter ECG}

On performing $48 \mathrm{~h}$ Holter ECG for our 55 cryptogenic stroke patients some patients as early as 4 days and with maximum of 42 days, two short runs of paroxysmal AF (pAF) were detected in 2 patients (3.7\%), both patients had their Holter done during the first 10 days from stroke onset.

\section{Contrast-enhanced transcranial duplex}

TCD was done for 55 CS patients for assessment of right to left shunting by detection of microembolic signals in MCA, 6 patients tested positive for shunting (17.1\%). All microembolic signals were less than 10 microemboli (grade 1).

On testing characteristics of TCD in detecting RLS compared to the gold standard of TEE, TCD sensitivity was $85.7 \%$, specificity was $100 \%$, negative predictive value was $96.55 \%$, and positive predictive value was 100\% (Table 2).

\section{Discussion}

The embolic appearance of most cryptogenic strokes implies that the cause is embolism from an occult source in the heart, aorta, or large artery. Cardioaortic conditions with a low or uncertain risk for embolic stroke include difficult to diagnose occult AF and related atrial cardiopathies, atrial septal abnormalities, complex aortic atheroma, and others.

In our study, TEE and contrast-enhanced TCD were done to compare RLS detection and results showed that TCD sensitivity was $85.7 \%$, specificity was $100 \%$, negative predictive value was $96.55 \%$, and positive predictive value was $100 \%$ denoting that TCD is a very good alternative tool for RLS detection as it is considered less invasive and has very good sensitivity compared to TEE and that was consistent with a study conducted in 2014 by Mojadidi and co-workers [10] who conducted a systematic review to assess intracardiac RLS detection using TCD compared with TEE and concluded that the weighted mean sensitivity and specificity for TCD were $97 \%$ and $93 \%$, respectively which is considered close to our study results.

In 2016, Joshua and co-workers [5] studied the frequency of detection of a RLS using TEE and TCD among patients with CS and concluded that TCD might be more sensitive than TEE for detection of RLS, which

Table 1 Abnormal findings in transesophageal echo (sources of cardioembolism)

\begin{tabular}{|c|c|c|c|}
\hline & & Frequency & Valid percent \\
\hline \multirow[t]{2}{*}{ Intra-atrial septal aneurysm } & Absent & 45 & 83.3 \\
\hline & Septal aneurysm & 9 & 16.7 \\
\hline \multirow[t]{2}{*}{ Patent foramen ovale } & Absent & 38 & 70.4 \\
\hline & Present & 16 & 29.6 \\
\hline \multirow[t]{2}{*}{ Detection of intra-cardiac thrombi } & No & 50 & 92.6 \\
\hline & Yes & 4 & 7.4 \\
\hline \multirow[t]{2}{*}{ Right to left shunting through trans-esophageal echo } & No & 43 & 81.1 \\
\hline & Yes & 10 & 18.9 \\
\hline \multirow[t]{3}{*}{ Other echo findings } & None & 47 & 87.0 \\
\hline & Descending aortic plaques & 5 & 9.3 \\
\hline & Filamentous mass in relation to aortic valve & 2 & 3.7 \\
\hline
\end{tabular}


Table 2 Association between right to left shunting through trans-esophageal echo and trans-cranial duplex

\begin{tabular}{|c|c|c|c|c|}
\hline & & \multicolumn{2}{|c|}{ Shunting through trans-cranial Doppler } & \multirow[t]{2}{*}{$p$ value } \\
\hline & & No shunting & Shunting & \\
\hline \multirow[t]{4}{*}{ Right to left shunting through trans-esophageal echo } & No & 28 & 0 & $<0.0001^{*}$ \\
\hline & & $100.0 \%$ & $0.0 \%$ & \\
\hline & Yes & 1 & 6 & \\
\hline & & $14.3 \%$ & $85.7 \%$ & \\
\hline
\end{tabular}

${ }^{*} p$-value calculated using likelihood ratio

misses some cases with substantial RLS, and might be valuable for prediction of recurrent stroke or transient ischemic attack in patients with PFO. TCD complements TEE for management of suspected paradoxical embolism and this is quite consistent with our study results. In our study, TEE revealed that 16 patients had PFO comprising $29.6 \%$ of patients, 9 patients had ASA comprising $16 \%$ of patients, of these patients 6 of them had both PFO and ASA comprising $10.9 \%$ of our study group, 4 patients had intra-cardiac thrombi comprising $7.4 \%$ of patients, and 5 patients had descending aortic plaques comprising $9.3 \%$ of patients noting that PFO and ASA prevalence in the general population is $25 \%$ and $2.42 \%$ respectively.

Regarding PFO percentage in our study, it was quite different from the results of the study done in 2009 by Alsheikh and co-workers [11] who found that PFO prevalence is up to $40 \%$ in patients with CS, suggesting that it may be conduit for stroke caused by paradoxical embolism rather than just an incidental finding which is considered higher percentage than that found in our study.

Yet our results were consistent with the study done in 2017 by Schneider and co-workers [12] who conducted a study on CS patients and concluded that the prevalence of PFO was higher in CS patients' group $30.9 \%$ compared to other stroke subtypes $21.9 \%$. At the end of this study, we explored that contrastenhanced TCD is considered a useful tool with high sensitivity for detection of right to left shunting yet TEE is needed to differentiate different causes of shunting.

\section{Study limitations}

The study sample still small to prove the high sensitivity of TCD in detection of right to left shunting.

\section{Conclusion}

We concluded that PFO is considered an important hidden etiology for ischemic stroke. Contrast-enhanced TCD is considered a sensitive method for detection of right to left shunting among PFO patients.

\section{Abbreviations}

C-TCD: Contrast-enhanced transcranial duplex; TEE: Transesophageal echo; RLS: Right to left shunting; PFO: Patent foramen ovale; CS: Cryptogenic stroke; AF: Atrial fibrillation; ASA: Interatrial septal aneurysm

\section{Acknowledgements}

Not applicable

\section{Authors' contributions}

All authors have read and approved the manuscript. SM conceived of the study and participated in its design and coordination and helped to draft the manuscript (FG). M Saleh conceived of the study and participated in its design and coordination and helped to draft the manuscript (FG). HK conceived of the study and participated in its design and coordination and helped to draft the manuscript (FG). EH participated in the sequence alignment (MT). AS conceived of the study and participated in its design and coordination and helped to draft the manuscript (FG). N S participated in the design of the study and performed the statistical analysis (ES).

\section{Funding}

This research did not receive any specific grant from funding agencies in the public, commercial, or non-profit sectors.

\section{Availability of data and materials}

All raw data will be available on the editor request through communication with the corresponding author.

\section{Ethics approval and consent to participate}

The study protocol was approved by Ain Shams University, Faculty of Medicine Research Ethics Committee FWA 000017585 in July 2016. Written informed consent was obtained from the patients participating in the study.

\section{Consent for publication}

A written informed consent for the publication was obtained from all the participants (or their first-degree relatives).

\section{Competing interests}

All authors declare that they have no competing interests.

\section{Author details}

${ }^{1}$ Neurology Department, Ain Shams University, Cairo, Egypt. ${ }^{2}$ Cardiology Department, Ain Shams University, Cairo, Egypt. ${ }^{3}$ Clinical Pathology Department, Ain Shams University, Cairo, Egypt. ${ }^{4}$ Ain Shams University, 19/1/ 42, P.O. 11841, El Rehab City, Cairo, Egypt.

Received: 7 July 2019 Accepted: 18 January 2021

Published online: 15 February 2021

References

1. Finsterer J. Management of cryptogenic stroke. Acta Neurol Belg. 2010;110: 135-47.

2. Putaala J, Tatlisumak T. Prime time for dissecting the entity of cryptogenic stroke. Stroke. 2014:45:950-2.

3. Handke M, Harloff A, Olschewski M, Hetzel A, Giebele A. Patent foramen ovale and cryptogenic stroke in older patients. N Engl J Med. 2007;357(22): 2262-8.

4. Cramer SC, Rordorf G, Maki JH, Kramer LA, Grotta JC, Burgin WS, Hinchey JA, Benesch C, Furie KL, Lutsep HL, Kelly E, Longstreth WT. Increased pelvic vein 
thrombi in cryptogenic stroke: results of the Paradoxical Emboli from Large Veins in Ischemic Stroke (PELVIS) study. Stroke. 2004;35(1):46.

5. Tobe J, Bogiatzi C, Munoz C, Tamayo A, Spence JD. Transcranial Doppler is complementary to echocardiography for detection and risk stratification of patent foramen ovale. Can J Cardiol. 2016;32:986-94.

6. Adams H, Bendixen B, Kappelle L, Biller J, Love BB, Gordon DL, Marsh EE. Classification of subtype of acute ischemic stroke. Definitions for use in a multicenter clinical trial. TOAST. Trial of Org 10172 in Acute Stroke Treatment. Stroke. 1993;24:35-41.

7. Easton J, Saver J, Albers G, Alberts MJ, Chaturvedi S, Feldmann E, Hatsukami TS, Higashida RT, Johnston SC, Kidwell CS, Lutsep HL, Miller E, Sacco RL. Definition and evaluation of transient ischemic attack: a scientific statement for healthcare professionals from the American Heart Association/American Stroke Association Stroke Council; Council on Cardiovascular Surgery and Anesthesia; Council on Cardiovascular Radiology and Intervention; Council on Cardiovascular Nursing; and the Interdisciplinary Council on Peripheral Vascular Disease. Stroke. 2009:40(6):2276-93.

8. Jauch EC, Saver JL, Adams HP, Bruno A, Connors JJ, Demaerschalk BM, Khatri P, McMullan PW Jr, Qureshi Al, Rosenfield K, Scott PA, Summers DR, Wang DZ, Wintermark M, Yonas H. Guidelines for the early management of patients with acute ischemic stroke: a guideline for healthcare professionals from the American Heart Association/American Stroke Association. Stroke. 2013;44:870-947.

9. Tobe J, Bogiatzi C, Munoz C, Tamayo A, Spence JD. Transcranial Doppler is complementary to echocardiography for detection and risk stratification of patent foramen ovale. Can J Cardiol. 2016:32:986 e9-e16.

10. Mojadidi MK, Roberts SC, Winoker JS, Romero J, Goodman-Meza D, Gevorgyan R, Tobis JM. Accuracy of transcranial Doppler for the diagnosis of intracardiac right-to-left shunt: a bivariate meta-analysis of prospective studies. JACC Cariovasc imaging. 2014;7(3):236-50.

11. Alsheikh-Ali AA, Thaler DE, Kent DM. Patent foramen ovale in cryptogenic stroke: incidental or pathogenic? Stroke. 2009;40:2349-55.

12. Schnieder M, Siddiqui T, Karch A, Bähr M, Hasenfuss G, Liman J, Schroeter M. Clinical relevance of patent foramen ovale and atrial septum aneurysm in stroke: findings of a single-center cross-sectional study. Eur Neurol. 2017; 78:264-9.

\section{Publisher's Note}

Springer Nature remains neutral with regard to jurisdictional claims in published maps and institutional affiliations.

\section{Submit your manuscript to a SpringerOpen ${ }^{\circ}$ journal and benefit from:}

- Convenient online submission

- Rigorous peer review

- Open access: articles freely available online

High visibility within the field

- Retaining the copyright to your article

Submit your next manuscript at $\boldsymbol{\nabla}$ springeropen.com 